\title{
ISTUNAF MAHKEMELERI
}

Yazan : Prof. Dr. Faruk. EREM

I. Istinaf mahkemelerinin leh ve aleyhindeki mütalaalar: 1. Tarihçi izahı

2. Istinafın her memlekette mevcut olduğu iddiası 3. Mahalli tesirler

4. Mesainin muayyen noktalara teksifi 5. üst mahkemelerin mürakabesi

6. Dâvanm iki defa görülmesi (A. Bilgili yargıçlar B. Dâvanın tekrarlanması

II. Kuruluş Kanunu tasarısı hükümlerinin tenkidi.

$\mathrm{Bu}$ günlerde memleketimizde Istinaf Mahkemelerinin yeniden kurulması fikri ortaya atılmış bulunmaktadır. Adalet Bakanlığınca "Genel Mahkemelerin kuruluşu hakkında kanun" tasarısı hazırlanmıştır. Bu tasarı İstinaf Mahkemelerinin kurulmasına ait hükümleri ihtiva etmektedir.

$\mathrm{Biz}$ bu yazımızda İstinaf Mahkemelerinin leh ve aleyhindeki mütalâaları nakletmekle iktifa edeceğiz. Bu sebeple yazımı bir araştırmadan ziyade nakilden ibarettir. Bu yazının ikinci kısmı kuruluş kanunu tasarısının İstinaf mahkemelerine tealluk eden hükümlerinin tenkidine hasredil. miştir.

\section{Istinaf mahkemelerinin leh ve aleyhlerindeki mütalâalar}

1) Tarihçi izah : İstinaf teşkilâtının lehinde olanlar bilhassa tarih vakıalara dayanarak bu müesseseyi izah etmek isterler. Böyle düşünenle re göre tarihin her devrinde mütekâmil bir adli teşkilât nerede kurulmu ise orada istinaf da mevcut olmuştur.

Böyle bir düsünce tarihi hakikatlere uygundur. Fakat doğru olma yan şey, tarihi vakıalardan istinaf lehinde çıamlan sonuçdur. Kısaca is tinaf tarihçesini görelim :

Roma'da, Krallik devrinde "Provocatio ad populum" müessesesir. rastlanmaktadır. Fakat bu bir istinafdan ziyade, kralın cezanın tatbikı dan evvel halkdan gelen bir meclisin mütalâasını almaktan ibaret idi. Cun huriyet devrinde "Provocatio" başka mahiyet aldı "Valeria Horatia , provocatione" kanunu bu günkü anlayısdan çok farkl bir istinaf usu ihdas etti. Bu yol ile halkin mahkemeler üzerinde bir çeşit tasarruf hak tanınmıștı. Bu yol bir üst adli mahkemede yeniden muhakeme edilmek d ğil, hakimlerin adaletinden kurtulup halk adaletine gitmek isteyen san 
lara bir imkândan ibaretti. Romada siyasî müesseselerin merkezileşmeğe başladığı sırada adlî hiyerarssinin de husule geldiği görülmektedir. Adli teşkilâtun hiyerarşik bir șekle sokularak merkezileşmesi bilhassa "apellatio" yolu ile sağlanmıştır. Bu yol şimdiki istinafa benzemektedir (1).

İstinafın asıl menșeini feodalitenin yıkılması sıralarında bulmak mümkündür. Feodalite devrinde adalet parçalanmıștı. Kralığın kuvvetlenmesi bilhassa kendini kaza sahasında gösteriyordu. Senyörlerin adaletinden şikâyetçi olanların kralın adaletine baș vurmak imkânı feodalite mahkemelerini yavaş yavaș kuvvetten düşürüyordu. Kralın mahkemesi bir ceșit milli mahkeme haline geldi. Kral mahkemesinin yetkisi hudutsuzlaștı, vazifesi çoğaldı. Daimi bir teşekküle olan ihtiyaç Paris Parlement'ının kurulmasına sebep oldu. Parlement selâhiyetini kraìdan aliyor, onun namına, fakat onun huzuru ve iştirâki olmaksızın adaleti yerine getiriyordu. Parlement XIV. asırda tam bir teşekkül haline geldi, artık daimi toplantı halinde idi ve azałarı sürekli bir sitatüye sahip oldular.

Fakat zaman geçtikçe iyi bir adliye teşkilâtının kurulması lüzumu kendini gösterdi. Bütün dâvaların son safhada bir tek noktada yani Paris Parlement'ında toplanmasını mahzurları ortaya çkdl. Krallık, feodalite adaletini zayıflatmak için Paris Parlement'ında neticelenen bir istinaf yolu kabul etmisti. Fakat artık birlik husule gelmis, feodalite mahkemelerinin korkulacak tarafı kalmamıştı, muhtelif vilâyetlerdeki eski mahkemeler, Paris Parlement'nı gibi, birer mahkeme haline gelmeğe bașladı. Bu parlement'lar mahalli mahkemelerin üstünde ve istinaf derecesinde idiler. Vilâyet Parlement'ları da yetkilerini artık senyölerden değil, kraldan alıyorlardı. Yargıçlar, Kralın yargıçarı idiler. XV. asırdan XVIII. asra kadar vilâyet parlement'lerinin ihdası işi tamamlandı. Bu suretle İstinaf monarşinin sağlam müesseselerinden biri haline geldi. Nihayet 1670 emirnamesi istinafa müteallik usul hükümlerini vaz'etti.

Büyük İhtilâl istinaf mahkemelerinin tekâmülüne son verdi. Çünkü stinaf kral adliyesinin, merkezi vilâyetlerde temsil ve koordinasyon va;ıtası idi. Krallık müessesesinin düşmesi ile esas rolü de ortadan kalktı. stinaf mahkemeleri ikinci plâna düştü. Bunun böyle olmasına iki mües:esenin kurulması doğrudan doğruya tesir etmiştir: Jürinin kurulması, Yeza muhakemeleri usulünde sifahilik prensibinin kabulü.

1670 emirnamesi ile kurulan istinaf usulü engizituvar usuldü. Bunu abii görmek lâzımdır. Ancak böyle bir usul kıralın mutlak salâhiyeti ile

(1) Romada istinai hakkunda bk. Garapin, Etude critique sur l'institution de Appel en matiere repressive, Paris, 1941; Şensoy, İstinaf (Broşür), tstanbul 1947, i. 5 . 
telif edilebilirdi. Fakat ihtilâl yaklaşmakta, hürriyet fikirleri ceza usulüne de sızmakta idi. 1788 de çıarılan bir emirname ile ceza dâvalarında suallerin önceden tayini usulï ortadan kaldırıldı, gerekçesiz hüküm vermek usulï menedildi. Fakat Fransız milleti daha fazlasını istiyordu. Cünkü komșu bir millet, Ingiliz milleti adliyesinde hürriyet rejimini kurmustu. Nihayet 1791 kanunu 1670 emirnamesini ilga etti ve yeni esaslara göre bir adli teşkilât ve usul kurulmuş oldu. Fransız kanun vazı bununla ananevi müesseseleri Ingiliz ceza usulü prensiplerine uydurmağa çalıştı. $\mathrm{Bu}$ kanun sorgu yargıcı yerine Itham Jürisi (Jury d'accusation) ikame etti. Cinayet dâvaları birisi başkan olmak üzere üç kişilik bir heyet ile on iki jüri azasına tevdi olundu. Ceza usulünde savcllı şahsiyet kazanmıştı. Eskiden ceza usulünün sok büyük bir kısmını beliğ etmiş olan ilk tahkikatın sahası daralmıs ve şifahi muhakeme usulü hakim olmuștu. Cinayet islerinde istinaf ortadan kalktı. Jürinin kararı hukuki noktalara münhasır olmak üzere yalnız temyize müsait görüldü. Fakat bilâhare haydutluk vakalarının artması, siyasî ihtiraslar yüzünden jürinin fena netice vermesi bir tepki uyandırdı ve Monarsi devrinin bazl müesseselerine avdet etmek lüzumu hissedildi. Nihayet 1789 danberi itham usulü (Pro. cedure accusatoire) ile engizituvar usul arasındaki mücadelede bir uzlas ma hasil oldu. Bu suretle her iki usule de tatbik sahası verilmis oluyordu Itham usulü hüküm safhasında, diğeri ilk tahkikatta tatbik edildi. Ni hayet Fransiz Ceza Muhakemeleri Usulü Kanunu, halen "muhtelit usul denilen usulü kabul etti ve bu usul Avrupa'nın belli başl usul kanunlarm kaynak oldu. Bu değişmeler sonunda cinayet dâvalarında istinaf temamiy le ortadan kalktı. Cünha ve kabahatlerde, yani nisbeden az ehemmiyet işlerde muhafaza edildi.

Hülâsa ettiğimiz bu tarihi gelişimden müellifler şu neticeyi çıkarmal tadırlar: Mahalli kaza mercilerini zayıflatmak için istinaf bir vasıta ol: rak kullanılmıştır. Merkezileştirme tamamlandıktan sonra istinaf merk zin o mahallerde temsiline hizmet etmiştir. Binnetice istinaf hukukî c makđan ziyade siyasî maksatlarla kurulmuștur (2). Rocco, istinafa "o ta çağ adalet anlayışını bakiyesi" nazarı ile bakar (3). Istisnafın huk kan müdafaası güçtür. Diğer taraftan istinaf tarihi gelişimi münhasir: demokratik gayelerden ibaret bulunan bir teskilât manzarası da arzetn yor. Yargılama işlerine, bir çeşit müdahale ve itimatsızlığın ifadesi oln si hasebiyle istinaf halk adeletinin tecellisine terk edilmis sahalardan $\mathbf{l}$ riç bırakılmıştır.

(2) bk. Prins, De l'appel dans l'organisation judiciaire repressive, Paris 1 (Garapin'den naklen s. 15), kşz. Garraud (Traité d'instruction criminelle, v. n. 11

(3) bk. Lavori preparatori del codice di procedura penale, VIII, 1929. 
2) Istinafin her memlekette mevcut olduğu mütalâası: İstinaf veya istinafa çok benzeyen müesseseler hemen her memlekette mevcuttur. Her memlekette mevcut bir müessesenin iyi bir müessese olduğuna inanmak lâzımdur.

Bu mütalâayı sathi bulmaktayız. Bazı memleketlerde istinafın mevcudiyeti yukarda arzettiğimiz tarihi zaruretler veya istinafin hakiki mahiyeti henüz anlașlmamıs devirlerde iyi bir müessese zannedilerek ihdas edilmiş olmasından ileri gelmektedir. Yine aynı memleketlerde istinafın ilgası veya mahiyetini tamamiyle değiştirmeğe matuf islâhat cereyanlarının mevcut olduğu da göze çarpmaktadır. Bu cereyan semeresini derhal vermeyecektir. Uzun bir tarihi gelişimi olan müesseselerin - teknik değersizlikleri anlașılmıș olsa bile - birdenbire ortadan kaldırılması, bilhassa demokratik rejime sahip memleketlerde, psikolojik bir mukavemetle karşlaşır. Kaldıki "en iyi teșkilât istinaf kabul etmeyendir" diyen ünlü müellifler de mevcuttur (4).

3). Mahalli tesirler: Ilk mahkemelerin mahalli tesirler altında kalabilecekleri, halbuki en ziyade vilâyet merkezlerinde bulunan istinaf mahkemelerinin bu tesirlerden azade karar verecekleri ileri sürülmektedir.

Bu mütalâa makul görülemez, hukukî sayılamaz. Kaide mahkemelerin "iyi yargıc" lardan müteşekkil olmasıdır. Mahalli tesirlere kendini kap. tırmamak her derecedeki yargıcta aranan vasıftır. Diğer taraftan "mahalli şartlar" 1 bilmek bir ceza dâvasının görülmesinde faydalı, hattâ bazı suçlar için lüzumludur.

4. Mesainin muayyen noktalara tèksifi: Dâva istinafa gelince meseeleler yavaş yavaș olgunlașır. Mahkemenin muayyen noktalar üzerinde nesaisini ve dikkatini toplayabilmesi imkân dahiline girmiştir.

Bu düşünce "hukukî meseler" için doğrudur. Bir dâvada hukukî mereseleler yavaş yavas olgunlaşır. Bu çeşit meseleler üzerind muhtlif yarıçarın durması faydasız değildir. Fakat bu işi yargitay esasen yapmakidir. Fiile teallûk eden meseleler (maddi meseleler)e gelince bunlar biэr tahkik, tesbit ve son safhada da takdir meseleleridir. Eğer tahkik ve ssbit işleri ilk mahkemede duruşma nihayetleninceye kadar ikmal ediieemis ise bunun istinafda başarılabileceğini ümit etmek yersiz olur. Kalki ceza yargıcları kazai faaliyctlerin de bir tahdide tabi tutulmamıslarr. Ceza dâvalarında iddia, müdafaa ve talepler yargıcı bağlamaz. Yarç adaletin tecellisi için dâva ile ilgili her hususu resen dahi tetkik ede-

(4) Ezcümle Prins (De l'appel...), (Garapin'den naklen s.s. 79). 
bilir. Istinaf yargıcı da bir duruşma yargıcı olduğuna göre mesainin teksifi imkânsızdır.

5. Üst mahkemelerin murakabası: Illk mahkemelerin üstünde istinaf mahkemelerinin bulunușu ilk mahkeme yargıçlarını daha titiz ve dikkatli olmağa sevkeder. Üst mahkemelerin murakabası eksik sorusturma ile iktifa edilmesine manî olur, keyfi hareketleri önler.

Bu mütalâa bir dereceye kadar varittir. Fakat üst mahkemelerin murakabasından doğacak mahzurlar karşısında bu mütalâanın değeri zayıflamaktadır. Yargıcı korkutan şey bir üst mahkemenin mevcut olması mıdır? Böyle bir korkudan büyük fayda beklenemez. Adaletin yargıç vicda. nındaki teminatı üst mahkeme korkusu değil, haksızlık etmek korkusudur. $6-w^{2 x}$

Bundan başka üst mahkemenin mevcut oluşu her zaman yargıcı daha titiz olmağa sevketmez. Hata edecek olursa onu düzeltecek bir makamm mevcudiyeti yargıcı daha az dikkatli yapabilir. Bu sebeple aynı işi bir kerre daha görecek olan istinaf mahkemesinin mevcudiyeti ilk mahkeme yargıcinın mesuliyet duygusunu azaltabilir, onu meslek vicdanından uzaklaştirabilir.

6) Dâvanın iki defa görülmesi: Bir dâvanın bir kere ilk mahkemede, bir kere de istinafda tetkik edilmesi verilecek hükmün doğru ve isabetli olmasını sağlar. İlk tetkikte gözden kaçan hususlar ikinci tetkikte nazara alınmis olur.

Ilk bakışda doğru gözüken bu mütalâanın haklı sayılması için istinaf mahkemesinin ilk mahkeme hakimlerinden daha bilgili yargıclardan müteşekkil olması ve dâvanın yeni başdan görülmesi lâzım gelmektedir. Bu hususlar üzerinde durmağa değer :

A. Bilgili yargıçlar : Dâva istinaf́da daha bilgili ve tecrübeli yargıçlar tarafından tekrar görülecek olursa ilk mahkeme yargıçlarının gözünden kaçanlar istinafda nazara alınmıs olabilir.

Bu mütalâaya şöyle cevap verilmektedir (5). Mademki yargıçlar daha bilgili ve tecrübeli olunca dâva daha iyi görülmektedir. $O$ halde neden mahkemeler, daha ilk kademede, bilgili ve tecrübeli yargıçlardan teşkil edilmesin? Neden dâvalar kâfi bilgi ve tecrübeye sahip olmayanlar elinde sürüncemede kalsın, sanıklar neden daha başdan itibaren aydın yargıçlara tevdi edilmesin?

B. Dâvanm tekrarlanması : İstinafda yapılacak ikinci tetkikin ilk mahkemede yapılmış olan birinci tetkikden daha isabetli netice verebilmesi için ikinci tetkikin birinci tetkikden daha iyi bir tarzda cereyan et-

(5) Prins (s. 128), (Garapin'den naklen ss. 104). 
mesi icap eder (6). Halbuki bunun aksi cereyan etmektedir. İstinaf mahkemelerinde tetkikat evrak üzerinde yapılmaktadır. Her ne kadar bazı memleketlerin usul kanunlarmda bir dereceye kadar şifahi usule yer verilmekte ise de tatbikatta suçun işlendiği mahalden uzak bulunan istinaf mahkemesinin bulunduğu mahalle kadar tanıkların getirilmesi gibi güçlükler yüzünden evrak üzerinde tetkikat ile iktifa olunmaktadır. Bu sebeple ilk mahkemenin duruşma zabitnamesi ile dâvayı incelemek zorunda kalan istinaf hakimleri gerçek ile teması sağlayamamaktadırlar. Bir müellif şöyle bir teşbih yapmiştır : İstinaf hakimi, hastayı kendi muayene eden bir doktor değildir, bir meslekdaşının raporuna göre hastalığa teșhis koyan bir doktordur (7).

Ceza Hukukunda "cezanın ferdileștirilmesi" bir prensip haline gelmiş bulunmaktadır. Dâva ile yakından temas temin edememiş bulunan istinaf yargıclarının cezanın ferdileştirilmesi bakımından, ilk yargıçan daha isabetli hareket ettiği de düşünülemez (8).

Dâvanın tekrarlanmasından bir mahzur daha doğar. Dâvanin mahkemede ilk defa görüulmüs ve bir kazaî karara bağlanmış olmasına rağmen. kısmen veya temamen yeni başdan görüimesi ilk mahkemeleri halkın gözünde alçaltacak ve ilk mahkemenin vaptığı işleri bir formalite haline illkilâp ettirecektir. Dâva hakkında asıl kararı istinafın vereceğini düşünen ilgililer, dâvalarına lâyıkı ile önem vermeyecekler, nasıl olsa istinafda haklarını koruyacakları dïsüncesi ile ilk mahkemenin muamelelerini küçümseyeceklerdir.

Adaletin bir an evvel tecelli etmesi lâzım iken dâvalarm uzaması her memlekette ciddi bir endişe doğurmaktadır. Bu gün ceza işlerinde esaslı bir islâhat kuvvetle müđ̧afaa edilen bir düşüncedir. Lüzumsuz olan her şeyi ceza usulünden kaldırmak, tiyatrovari münakaşalara mani olmak, müdafaanın prestişini ve ciddi karakterini kuvvetlendirmek, usul hiylelerini cezalandırmak, kısaca hakiki adaletin şekil adaletine üstünlüğünü sağlamak ve ceza ișlerinde adalet istekleri ile kabili telif bir sür'at temin etmek lüzumu kendini hissettirmektedir. İstinafın mevcudiyeti bu düșüncelere pek de uygun görülmemektedir.

Biri ilk, diğeri istinaf olmak üzere iki mahkemenin mevcudiyeti ve bunların aynı dâvanın aynı noktalarını tahkike yetkili sayılması ilk mah-

(6) Bk. Garraud, V. n. 1627 (s. 11, nt. 10); kşz. Vassali, La riforma della procodura penale tedesca, Citta di castello, 1941, s. 65 "L'appello".

(7) Andrieux, Supression des cours d'appel, Revue prenitentiaire et de droit pénal, 1922 s. 249.

(8) Bu hususta bli. Garapin, ss. 96; Belloni, L'individualisation de la peine, Révue internationale de droit penal, 1933, ss. 332 
kemenin hükümleri hakkında bir haksızlık veya hata karinesi - veya hiç olmazsa - süuphesi yaratmıs olacaktır. Ilk mahkeme yargıcları hakkında bir itimatsıılığın zımnen ifadesi demek olan istinaf teskilâtının bu bakımdan da müdafaası güçdür. Balzac şöyle demişti (9) : Yargıçlara itimad etmemek bir cemiyetin çözülmeğe başlaması demektir. Müiesseseyi başka temeller üzerine yeniden kurunuz, ondan sonsuz teminat isteyiniz, fakat ona inanını.

\section{Kuruluş kanunu tasarısı hükümlerinin tenkidi :}

Memleketimizde istinaf mahkemelerinin kurulmasinda fayda melhuz olup olmadığ hususuna gelince: tasarıda sadece üst mahkemelerin kuruluşu nazaria alınmamıştır. Halbuki bir teşkilât kurulmadan evvel bu teşkilât ile tahakkuk ettirilmek istenilen hususun tayini lâzımdir. Bu sebeple evvelâ üst mahkemelerde takip edilmesi istenilen muhakeme usulünün belirtilmesi icap etmektedir. İstinafin hayırlı neticeler verebilmesi her seyden evvel takip edilecek muhakeme usulüne bağlıdır. Muhakemenin şifahi yol ile tekrarından, evrak üzerinde tetkikata münhasır usule kadar derece dederece değişen muhakeme usulü şekilleri düşünülebilir. Bunlardan hangi usul memleketimizde tatbik edilecektir? Gerek bu tasanda, gerek TBMM. nde bulunan usul kanunu tâdilâtı tasarısında bu hususa dair bir sarahat mevcut değildir. Muhakeme usulï tayin edilmeden teskilât kurmak doğru olmaz. Çünkü kurulması istenilen teşkilâtın arzu edilen usulü tahakkuk ettirmeğe elverişli olup olmadığını kesdirmek imkânsızdır.

Eğer teminatlı bir adalet sağlamak gayesi takip ediliyorsa istinafda imkân nisbetinde geniş bir şifahi usulü muhakemeye yer vermek lâzım gelecektir. Tasarı gerekçesinde (sayfa 24) yirmi, yirmi bes yerde üst mahkeme kurulabileceğinden bahsedilmektedir. Yirmi, yirmi beş üst mahkeme teşkiline maddeten imkân bulunup bulunamayacağı üzerinde tereddüt edilebilir. Bir üst mahkeme kadrosu ve masrafları düşünülecek olursa bu günkủ şartlar altında bu adetlerin gerçeğe yaklaşıp yaklaşamıyacağı düşündürücü bir meseledir. Bu kadar üst mahkeme kurulmuş olsa bile yine ihtiyaça kâfi gelemiyecektir. Çünkü memleket 20 veya 25 üst mahkeme bölgesine aymlmış olacaktır. Eğer şifahi usule az çok yer verilecek olursa - ki bunda zaruret vardır - üst mahkeme merkezlerine sadece tanıkların nasıl getirilebileceğini ve bu ișin doğuracağı güçlükleri ve halk üzerindeki tesirini düşünmek lâzım gelmektedir.

Diğer taraftan üst mahkemelerin, ilk mahkemelere nazaran daha üs-

(9) Bouchardon (- dan naklen), Le magistrat, Paris 1926, s. 123. 
tün vasıfta yargıçlara ihtiyaç göstereceği ve bu derecede yetișmiș yargıçların adedinin kâfi olup olmadığını da düsüunmek lâzımdır.

Üst mahkeme namı altında bir derece mahkemesinin ihdası dâvaların görülmesini de uzatacaktır. Her ne kadar tasamda sulh ișlerinin üst mahkemelerde kesin karara bağlanacağ kemeye gitmeyeceği bildirilmekte ise de asliye işlerinin miktarı uzayacak dâvalamn çokluğunu göstermeğe kâfidir.

Bundan başka ağır ceza işleri ile sulh işlerinin istinafa tabi tutulması keyfiyeti üzerinde de durmak lâzimdrr :

Yabancı memleketlerin çoğunda ağır cezalı ișler istinafa tabi değildir. Tasarıda ağır cezall işlerin istinafdan hariç tutulmasına sebep gerek yabanci memleketlerdeki bu durum gerekse evvelce memleketimizde istinaf teskilâtı mevcut iken cinayet mahkemesi kararlarının istinafdan hariç bırakılmıs olması keyfiyetidir. Yabancı memleketlerin ağır ceza işlerini istinafa tabi tutmamaları sebebi şudur: Ağır ceza işleri jürili mahkemelerde görülmektedir. Dâvanin esasına jüri karar verir. Jüri halk adaletini temsil eder. Bu sebeble halk adaleti mümessillerinin verdikleri kararlar adliye mahkemelerinden ibaret bulunan istinaf mahkemesinde tetkike tabi tutulamaz. Jürili mahkemeler hakkındaki bu gerekçenin memleketimiz için varit olmadığı aşikârdır. Eskiden memleketimizde istinaf mevcut iken bu husus nazara alınmış, cinayet işlerinin istinafa tabi olmamasından doğacak müsavatsızlık cinayet işlerine has bazı tetbirlerle izale edilmiști (10) (11). Bu çeşit tedbirlerin yeni tasarıda ittihaz edilmediği görülmektedir. Bu vaziyet karșısıinda şu mantıksızlık ortaya çıkmaktadır : Ağr ceza işlerinden daha hafif olan asliye işleri biri istinaf diğeri temyiz olmak üzere iki teminata tabi tutulduğu halde ağır ceza işleri yalnız bir teminata tabi tutulmustur.

Bundan baskka sulh islerinin istinafda kesin karara bağlanması (tasarı madde 25, son fikra) ve bu suretle Yargitaya intikal etmemesinin de izahı güçdür. Tasarıdaki hüküm şşudur: İkinci derecede görülen ceza dâvalarına ait hüküm ve kararlardan sulh işi sayllanlara teallûk edenlex hakkındaki üst mahkeme hüküm ve kararları kesindir". Tasarı gerekçesinde şöyle denilmektedir : "Üst mahkemelerin (İstinaf mahkemelerinin) küçük birer temyiz mahkemesi haline düsmesi ve netice itibariyle ictihad ihtilâflarının artması, yani üst mahkemelerin aynı. mesele hakkında yek-

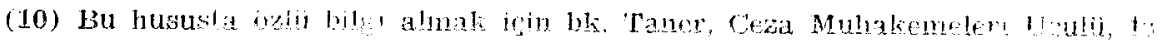
tanbul, 1945, ss. 32 .

(11) Memleketimizde istinaf tarihçesi hakkinda bk. Sensoy, tstinaf (Broguir), tstanbul, 1947 s. 8. 
diğerine aykırı karar vermeleri hakkındaki mülâhaza bir dereceye kadar varit olabilir. Ancak bu mahzur hiç bir vakit sulh işlerinin kesin olarak üst mahkemelerce tetkikine engel olmamalıdır. Çünkü yürürlükte bulunan Hukuk Muhakemeleri Usulï Kanununda yirmi beş liraya kadar olan alacak dâvalarının asliye mahkemelerince kesin olarak görüleceği kabul edilmiş olduğu halde yirmi yll geçen bir süre içinde içtihat ihtilâflarma meydan verildiği hakkında bir iddia ve şikâyet ișitilmemiștir”. Bu gerekçe tatmin edici değildir. Uzun zamandanberi içtihat ihtilâflarından dolayı bir şikâyetin mevcut olmadığı hususu bir gerekçeye mesnet olamaz. Bu şikâyetlerin mevcut olmaması belki de ilk derecedeki mahkemelerden öteye taşmadığından, hâdiselerin bilinmemiş, meçhul kalmış olmasındandır. $\mathrm{Bu}$ işler istinafa intikal edince ve muhtelif istinaf mahkemeleri arasinda içtihat ayrilıkları bariz bir hale gelince belki de şikâyetlerin önünü almak kabil olamayacaktır. Diğer taraftan içtihat ayrılıkları yalnız muhtelif istinaf mahkemeleri arasinda değil, istinaf mahkemeleri ile Yarg1tay arasında da kendini gösterebilecektir. Ust mahkemelerin kesin kararına mevzu teşkil eden işlerle Yargitaya kadar gidebilen işler arasında kanunların aynı hükümlerine tâbi hususlar (TCK. nun umumî hükümleri gibi) daima mevcut olabilecektir. Muhtelif yargı organları arasında içtihat ayrilkları adalete olan güveni sarsabilir.

Tasarı gerekçesinin 26. sahifesinde İstinaf mahkemesi birinci başkanının istinafın bulunduğu çevrede "Adalet Bakanının mümessili" olduğundan bahsedilmektedir. Yazımızın ilk kısminda Parlement'ların vilâyetlerde kural adaletini temsil ettiğini izah etmiştik. Bu husus ile tasarı gerekçesinde istinaf mahkemesi başkanının Adalet Bakaninın mümessili telâkki edilmesi arasında bir yakınlık gözükmektedir. Zamanımizda kaza sahasinda merkezin diğer mahallerde temsili ve bilhassa icra kuvvetine mensup bulunan bir bakanın bir yargıç tarafından temsili kabili müdafaa bir fikir değildir. 